\title{
COMPORTAMENTO FISIOLÓGICO DE SEMENTES DE MANGOSTÃO (Garcinia mangostana L.) SUBMETIDAS A DIFERENTES PERÍODOS DE FERMENTAÇÃO DA POLPA ${ }^{1}$
}

\author{
WALNICE MARIA OLIVEIRA DO NASCIMENTO2; ANDREZA TAVARES TOMÉ ${ }^{3}$; \\ JOSÉ E. URANO DE CARVALHO²; CARLOS HANS MÜLLER ${ }^{2}$
}

\begin{abstract}
RESUMO - As sementes de mangostão, logo após a retirada do fruto, apresentam polpa aderida ao tegumento. Este material, rico em açúcar, favorece a proliferação de patógenos, capazes de interferir na germinação das sementes indevidamente limpas. Com o objetivo de estudar o efeito da retirada da polpa por fermentação sobre a germinação das sementes, foram testados os períodos de $0 ; 24 ; 48 ; 72$ e 96 horas de fermentação em água. Para tanto, após as fermentações, as sementes foram semeadas em bandejas contendo, como substrato, uma mistura de areia e serragem na proporção de $1: 1$, à temperatura de $26 \pm 2^{\circ} \mathrm{C}$ e umidade relativa de $86 \pm 3 \%$, fazendo-se a contagem diária do número de plântulas normais. As sementes foram avaliadas pelos testes de percentagem de germinação, velocidade de germinação e tempo médio de germinação. O delineamento foi o inteiramente casualizado, com quatro repetições de 50 sementes cada. Os dados obtidos evidenciaram que a fermentação das sementes por 48 horas facilitou a remoção da polpa e proporcionou a maior germinação (86\%), diferindo significativamente dos demais tratamentos.
\end{abstract}

Termos para indexação: germinação, tempo médio de germinação, Clusiaceae.

\section{PHYSIOLOGY BEHAVIOR OF SEEDS OF MANGOSTEEN (Garcinia mangostana L.), AS AFFECT BY DIFFERENT FERMENTATION PERIODS OF THE PULP}

\begin{abstract}
The mangosteen seeds right after the retreat of the fruit present great amount of pulp stucked to the tegument. This rich material in sugar favors the diseases proliferation, which interfere in the germination when the seeds are not properly clean. With objective of studying the effect of the different times of fermentation on the germination of the seeds, a experiment was realized, with five treatments $0,24,48,72$ and 96 hours of fermentation in water. The experiment was conducted following as a completely randomized design and treatments were replicated four times with 50 seeds each, sowed in trays containing as substratum a mixture of sand and sawdust in the proportion of $1: 1$, under environment temperature $26 \pm 2^{\circ} \mathrm{C}$ and relative humidity of $86 \pm 3 \%$. The following tests were used for evaluating the seeds: germination test, emergence speed, average germination time. The number of normal seedling was assessed on a daily basis. The results evidenced that the fermentation of the mangosteen seeds for 48 hours provided better germination percentage $(86 \%)$, differing significantly from the other treatments.
\end{abstract}

Index terms: germination, mean germination time, Clusiaceae.

Entre os inúmeros frutos tropicais, o mangostão (Garcinia mangostana L.) é considerado o principal do trópico asiático, devido ao sabor e aroma agradáveis de sua polpa. Por isso, é tido como a mais saborosa fruta do mundo, "o manjar dos deuses". Árvore de porte médio a alto, podendo atingir $25 \mathrm{~m}$ de altura, pertence à família Clusiaceae, sendo originária do Sudeste asiático. Atualmente, encontra-se cultivado em alguns países de clima tropical da África, América do Sul e Austrália. No Brasil, as regiões que apresentam condições climáticas semelhantes às do local de origem, podem ser consideradas favoráveis ao cultivo do mangostãozeiro em escala comercial (Müller et al., 1995).

Alguns autores, como Roberts \& Ellis (1973), Roberts \& King (1980) e Chin (1989), classificaram a semente de mangostão como recalcitrante, pois a perda da umidade e o armazenamento a frio têm sido mencionados como responsáveis pela redução da viabilidade desta espécie. O curto período de viabilidade das sementes de mangostão foi considerado, por Winters \& Rodrigues-Colon (1953), prejudicial à sua propagação e dispersão.

Porém, estudos desenvolvidos por Müller et al. (1991) demonstraram que as sementes de mangostão podem ser armazenadas no fruto por períodos de até 35 dias, acondicionadas em sacos de plástico, sem que ocorram danos à qualidade fisiológica.

Em condições favoráveis de temperatura e umidade, as sementes germinam entre onze e quinze dias após a semeadura. É freqüente a ocorrência de poliembrionia nas sementes de

1 (Trabalho 183/2000). Recebido: 21/08/2000. Aceito para publicação: 28/08/2001.

2 Pesquisador da Embrapa Amazônia Oriental, Laboratório de Ecofisiologia e Propagação de Plantas, Caixa Postal, 48, CEP 66017-970, Belém, PA. walnice@cpatu.embrapa.br

3 Bolsista do Convênio PIBIC/CNPq/Embrapa. 
mangostão, isto é, a emergência de duas plântulas de uma única semente (Müller et al., 1995).

De acordo com Cox (1976), as sementes de mangostão sem a polpa são revestidas por uma membrana que as preserva do processo de dessecação. No entanto, após o beneficiamento, as sementes ainda apresentam grande quantidade de polpa aderida ao tegumento. Este material, rico em açúcar, favorece a proliferação de patógenos, que interferem na germinação quando as sementes não são devidamente limpas.

O presente trabalho teve por objetivo estudar a influência de diferentes tempos de fermentação da polpa sobre o desempenho fisiológico de sementes de mangostão.

O experimento foi conduzido no Laboratório de Ecofisiologia e Propagação de Plantas da Embrapa Amazônia Oriental, em Belém- PA.

As sementes utilizadas foram retiradas de frutos em completo estádio de maturação, colhidos de matrizes estabelecidas no Campo Experimental de Fruteiras. O delineamento adotado foi o inteiramente casualizado, com cinco tempos de fermentação e quatro repetições de 50 sementes cada.

Após a extração manual dos frutos, as sementes foram fermentadas imersas em água, durante $0 ; 24 ; 48 ; 72$ e 96 horas, em recipiente de plástico, à temperatura ambiente. Após a fermentação, as sementes foram lavadas em água corrente e atritadas contra peneira de malha fina, até que a polpa fosse retirada por completo. A semeadura foi feita em bandejas de plástico, contendo como substrato mistura de areia lavada e de serragem curtida, na proporção volumétrica de 1:1, previamente esterilizado em estufa a $120^{\circ} \mathrm{C}$ durante duas horas.

As sementes foram mantidas à temperatura de $26 \pm 2^{\circ} \mathrm{Ce}$ umidade relativa de $86 \pm 3 \%$. Foram consideradas germinadas as sementes que deram origem a plântulas normais. No caso de sementes que deram origem a mais de uma plântula normal, somente uma foi contada para fins de cálculo de percentagem, tempo médio e índice de velocidade de germinação (Brasil, 1992). A germinação das sementes foi verificada diariamente, anotandose o número de sementes germinadas em cada parcela. A contagem das plântulas foi realizada, do nono ao trigésimo dia após a semeadura. Para fins de estimativa do índice de velocidade e do tempo médio de germinação, foram utilizadas as equações propostas por Kotowiski, citada por Silva \& Nakagawa (1995).

Os dados obtidos foram analisados estatisticamente em delineamento inteiramente casualizado e as médias comparadas pelo teste de Tukey, a 5\% de probabilidade.

Os dados para percentagem de germinação, tempo médio de germinação e índice de velocidade de germinação estão apresentados na Tabela 1.

Os dados obtidos evidenciaram que a fermentação das sementes, por 48 horas, facilitou a remoção da polpa e proporcionou a maior germinação (86\%), diferindo significativamente dos demais tratamentos.

De modo geral, as fermentações por 72 e 96 horas foram prejudiciais à germinação. Em relação aos demais tratamentos, esse efeito ampliado com o aumento do tempo de fermentação, provavelmente, esteja associado ao período de anoxia ocorrido na imersão em água; verificou-se que, com o aumento do tempo de fermentação do material, houve emanação de odor característico provocado pelo desprendimento de gases. Ao examinar os efeitos da remoção da mucilagem na qualidade das sementes de pepino e tomate, Nascimento et al. (1994) detectaram que a germinação era afetada à medida que o tempo de fermentação (pepino) e a temperatura (tomate) foram elevados. Resultados semelhantes foram encontrados por Santos (1996), em sementes de cupuaçu, quando foi utilizado tratamento envolvendo fermentação em água por períodos iguais ou superiores a 96 horas.

Através de avaliação visual, verificou-se que as sementes não fermentadas ofereceram maior dificuldade para a retirada da polpa, apresentando expressivos danos no tegumento e nos cotilédones, o que pode ter provocado a redução na percentagem de germinação.

A velocidade de germinação mostrou desempenho menos satisfatório para as sementes submetidas a 72 horas de fermentação. Este índice está associado ao vigor das sementes; assim sendo, fica também evidenciado que as sementes assim processadas tiveram seu vigor afetado.

As sementes de mangostão apresentaram germinação com início variando entre nove e doze dias e com término entre 19 e 26 dias após a semeadura. Esses resultados estão de acordo com os encontrados por Müller et al. (1995). Entretanto, nas sementes que não sofreram fermentação, a germinação foi mais rápida, iniciando aos nove dias e terminando aos 19 dias após a semeadura.

TABELA 1 - Percentagem, tempo médio e velocidade de germinação em sementes de mangostão submetidas a diferentes períodos de fermentação da polpa.

\begin{tabular}{cccc}
\hline $\begin{array}{c}\text { Fermentação } \\
(\text { hora })\end{array}$ & $\begin{array}{c}\text { Germinação } \\
(\%)\end{array}$ & $\begin{array}{c}\text { Tempo médio de } \\
\text { germinação } \\
(\text { dia })\end{array}$ & $\begin{array}{c}\text { Velocidade } \\
\text { Germinação }\end{array}$ \\
\hline 0 & $75,36 \mathrm{~b}^{*}$ & $13,28 \mathrm{a}$ & $0,08 \mathrm{a}$ \\
24 & $76,36 \mathrm{~b}$ & $15,17 \mathrm{~b}$ & $0,07 \mathrm{~b}$ \\
48 & $85,93 \mathrm{a}$ & $15,43 \mathrm{~b}$ & $0,07 \mathrm{~b}$ \\
72 & $54,75 \mathrm{c}$ & $15,19 \mathrm{~b}$ & $0,07 \mathrm{~b}$ \\
96 & $0 \mathrm{~d}$ & $0 \mathrm{c}$ & $0 \mathrm{c}$ \\
\hline
\end{tabular}

* Médias seguidas da mesma letra não diferem entre si, pelo teste de Tukey, a 5\% de probabilidade. 
Com base no exposto, pode-se concluir que:

1. A remoção da polpa mediante a fermentação em água, por 48 horas, facilita a remoção da polpa e afeta positivamente a germinação das sementes.

2. A fermentação em água, em período superior a 72 horas, afeta negativamente o vigor das sementes.

\section{REFERÊNCIAS BIBLIOGRÁFICAS}

BRASIL. Ministério da Agricultura. Regras para análise de sementes. Brasília: SNAD/CLAV, 1992.365p.

CHIN, H.F. Recalcitrant seeds. Taipei: Food \& Fertilizer Technology Center, 1989. 16p. (Extension Bulletin, 288).

COX, J.E.K. Garcinia mangostana - mangosteen. The propagation of tropical fruit trees. East Malling: Commonwealth Bureau of Horticulture and Plantation Crops, 1976. p.361-375. (Horticultural Review, 4).

MÜLLER, C.H.; FIGUEIREDO, F.J.C.; MÜLLER, N.R.M. Armazenamento de sementes de mangostão. Belém: EMBRAPACPATU, 1991. 15p. (Circular Técnica, 58).

MÜLLER, C.H.; FIGUEIREDEO, F.J.C.; NASCIMENTO, W.M.O. do; CARVALHO, J.E.U. de; STEIN, R.L.B.; SILVA, A. de B.;
RODRIGUES, J.E.L.F. A cultura do mangostão. Brasília: EMBRAPA-SPI, 1995. 56p. (Coleção Plantar, 28).

NASCIMENTO, W.M.; PESSOA, H.B.S.V.; SILVIO, J.B.C. Remoção da mucilagem e seus efeitos na qualidade das sementes de pepino e tomate. Horticultura Brasileira, v.11, n.2, p.169$172,1994$.

ROBERTS, E.H.; ELLIS, R.H. Predicting the storage life of seeds. Seed Science and Technology, Zurich, v.1, n.2, p.499-514, 1973.

ROBERTS, E.H.; KING, M.W. The characteristics of recalcitrant seeds. In: CHIN, H.F.; ROBERTS, E.H. Recalcitrant Crop Seeds, Malasysia: Kuala Lumpur: Ed. Tropical Press, 1980. p.1-5.

SANTOS, W.N.M. dos. Eficiência de diferentes métodos de remoção de resíduos de polpa e sua influência na germinação de cupuaçu (Theobroma grandiflorum (Will ex-Sprend) (Schum). 1996. 137. Monografia (Trabalho de Graduação).

SILVA, J.B.C.; NAKAGAWA, J. Estudo de fórmulas para cálculo da velocidade de germinação. Informativo ABRATES, Londrina. v.5, n.1, p.62-73, 1995.

WINTERS, H.F.; RODRIGUEZ-COLON, F. Storage of mangosteen seeds. Proceedings of the American Society for Horticultural Science, Alexandria, n.1, v. 6, p. 304-306, 1953. 